\title{
Improvement in quality of life and psychological symptoms after treatment for primary aldosteronism: Asian Cohort Study
}

Yen Kheng Tan'1, Yu Heng Kwan², David Choon Liang Teo ${ }^{3}$, Marieke Velema ${ }^{4}$, Jaap Deinum ${ }^{5}$, Pei Ting Tan 6 , Meifen Zhang ${ }^{7}$, Joan Joo Ching Khoo ${ }^{7}$, Wann Jia Loh ${ }^{7}$, Linsey Gani ${ }^{7}$, Thomas FJ King ${ }^{7}$, Eberta Jun Hui Tan ${ }^{7}$,

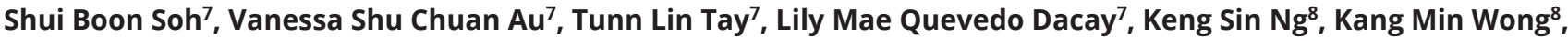
Andrew Siang Yih Wong ${ }^{9}$, Foo Cheong Ng ${ }^{10}$, Tar Choon Aw ${ }^{11}$, Yvonne Hui Bin Chan', Khim Leng Tong ${ }^{12}$, Sheldon Shao Guang Lee ${ }^{12}$, Siang Chew Chai ${ }^{12}$ and Troy Hai Kiat Puar ${ }^{7} 7$

${ }^{1}$ Duke-NUS Medical School, SingHealth, Singapore, Singapore

${ }^{2}$ Department of Internal Medicine, Singapore General Hospital, Singapore, Singapore

${ }^{3}$ Department of Psychological Medicine, Changi General Hospital, Singapore, Singapore

${ }^{4}$ Division of Endocrinology, Department of Internal Medicine, Radboud University Medical Centre, Nijmegen, The Netherlands

${ }^{5}$ Division of Vascular Medicine, Department of Internal Medicine, Radboud University Medical Centre, Nijmegen, The Netherlands

${ }^{6}$ Department of Clinical Trials Research Unit, Changi General Hospital, Singapore, Singapore

${ }^{7}$ Department of Endocrinology, Changi General Hospital, Singapore, Singapore

${ }^{8}$ Department of Diagnostic Radiology, Changi General Hospital, Singapore, Singapore

${ }^{9}$ Department of Surgery, Changi General Hospital, Singapore, Singapore

${ }^{10}$ Department of Urology, Changi General Hospital, Singapore, Singapore

${ }^{11}$ Department of Laboratory Medicine, Changi General Hospital, Singapore, Singapore

${ }^{12}$ Department of Cardiology, Changi General Hospital, Singapore, Singapore

\begin{abstract}
Background: In addition to increased cardiovascular risk, patients with primary aldosteronism (PA) also suffer from impaired health-related quality of life (HRQoL) and psychological symptoms. We assessed for changes in $\mathrm{HRQ}$ L $\mathrm{L}$ and depressive symptoms in a cohort of Asian patients with PA, after surgical and medical therapy.

Methods: Thirty-four patients with PA were prospectively recruited and completed questionnaires from 2017 to 2020. HRQoL was assessed using RAND-36 and EQ-5D-3L, and depressive symptoms were assessed using Beck Depression Inventory (BDI-II) at baseline, 6 months, and 1 year post-treatment.

Results: At 1 year post-treatment, significant improvement was observed in both physical and mental summative scores of RAND- $36,+3.65, P=0.023$, and +3.41

$P=0.033$, respectively, as well as four subscale domains (physical functioning, bodily pain, role emotional, and mental health). Significant improvement was also seen in EQ-5D dimension of anxiety/depression at 1 year post-treatment. Patients treated with surgery $(n=21)$ had significant improvement in EQ-5D index score post-treatment and better EQ-5D outcomes compared to the medical group $(n=13)$ at 1 year post-treatment. $37.9,41.6$ and $58.6 \%$ of patients had symptoms in the cognitive, affective and somatic domains of BDI-II, respectively. There was a significant improvement in the affective domain of BDI-II at 1 year post-treatment.

Conclusion: Both surgical and medical therapy improve HRQoL and psychological symptoms in patients with PA, with surgery providing better outcomes. This highlights the importance of early diagnosis, accurate subtyping and appropriate treatment of PA.
\end{abstract}

\author{
Key Words \\ - adrenalectomy \\ - hyperaldosteronism \\ - quality of life \\ - depression \\ - mineralocorticoid receptor \\ antagonists \\ - treatment outcome
}

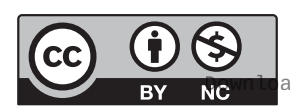

This work is licensed under a Creative Commons Attribution-NonCommercial 4.0 International License. ded from Bioscientifica.com at 04/26/2023 01:10:53PM
Endocrine Connections (2021) 10, 834-844 


\section{Introduction}

Hypertension is the largest single contributor to the global burden of disease and mortality (1), and 5-20\% of all patients are estimated to suffer from primary aldosteronism (PA). Compared to patients with essential hypertension, patients with PA have an increased risk of cardiovascular disease and renal failure $(2,3)$. In addition, several studies have shown that patients with PA have a poorer health-related quality of life (HRQoL) and may also suffer from anxiety and depression $(4,5)$. Generally, bilateral PA is treated with mineralocorticoid receptor (MR) antagonists, while unilateral PA is managed with unilateral adrenalectomy (6). Studies have found better cardiovascular events and HRQoL outcomes following surgical treatment $(2,5)$. Adrenal vein sampling (AVS) is required to differentiate unilateral from bilateral PA and is technically challenging to perform (7). If surgery leads to better outcomes than medical treatment, then it will be ideal for all patients to undergo subtype testing and will be offered the appropriate treatment (6).

There has been increasing attention in recent years towards not just physician-identified issues but patientreported outcome measures (PROM). Hence, PROMs have been developed to assess general HRQoL (8). PROMs cover multiple domains of health that are influenced by patient's subjective experiences, perceptions, and beliefs (9). These include pain, physical functioning, mobility, mood and other important areas of functioning. To date, few studies have examined HRQoL outcomes in PA cohorts $(5,10,11)$, and none have been conducted in an Asian cohort. Previous studies have shown that HRQoL appears to be lower in patients with PA compared to the general population $(5,10,11)$. While there is improvement after treatment, patients who have undergone adrenalectomy appear to respond better than those on long-term medications. In addition, other studies have shown that patients with PA have significant psychological symptoms, which may improve after treatment (5).

Hence, in this prospective observational study, we aimed to assess for both HRQoL and depressive symptoms in a cohort of patients with PA after appropriate treatment with either surgical or medical therapy based on the underlying subtype of PA. Our secondary aim was to compare the effects of surgical and medical therapy.

\section{Materials and methods}

\section{Study design and patients}

We performed a prospective, observational clinical study to assess for improvement in patient outcomes after treatment of PA. The PA PACES study (prospective study assessing blood pressure, cardiovascular, endothelial and other outcomes post-surgical and medical treatment in patients with PA) was conducted in a tertiary centre, Changi General Hospital, from January 2017 to September 2020. The study was registered with clinicaltrials.gov (NCT03174847), approved by SingHealth Centralised Institutional Review Board (CIRB Reference number 2016/2888), and informed consent was obtained from all participants.

We included patients of age 18 years or older, with a confirmed diagnosis of PA in accordance with the 2016 Endocrine Society Guidelines (6). For the purpose of assessing HRQoL, patients were required to be Englishliterate. From July 2017, Chinese-literate patients were included and they completed European Quality of Life-5 Dimensions (EQ-5D-3L) (Chinese version). Exclusion criteria were patients with adrenal carcinoma, severe or terminal co-morbidity that interfered with possible treatment or HRQoL, or glucocorticoid-remediable aldosteronism. Prior to hormonal tests, antihypertensive medications which interfered with renin and aldosterone levels (e.g. ACE-inhibitors, diuretics) were discontinued for at least 2 weeks in most patients, while potassiumsparing diuretics were discontinued for at least 6 weeks in all patients. Hypokalaemia, if present, was corrected with potassium supplementation, aiming for serum potassium $\geq 3.5 \mathrm{mmol} / \mathrm{L}$ before hormone measurements. Plasma aldosterone concentration (PAC) and plasma renin activity (PRA) were determined in all patients as previously reported (12). Patients underwent i.v. seated saline infusion test and all patients had a post-saline infusion PAC $\geq 140 \mathrm{pmol} / \mathrm{L}$ (6). Patients underwent a thin-slice CT imaging of the adrenal glands. Unilateral adenoma was defined as a unilateral adrenal nodule of at least $8 \mathrm{~mm}$, while the contralateral gland was normal and not enlarged. Patients seeking a surgical cure underwent adrenal vein sampling (AVS) to determine lateralisation. AVS was performed under continuous corticotropin, with sequential cannulation of the right adrenal vein, left adrenal vein, and infra-renal inferior vena cava (IVC). Selectivity index was calculated by the adrenal vein cortisol to IVC cortisol ratio, and a gradient of at least three was taken to be successful. Lateralisation ratio was calculated by the higher adrenal vein aldosteroneto-cortisol ratio divided by the contralateral side. Lateralisation ratio greater than four was consistent with unilateral PA and a ratio below three consistent with bilateral PA. Patients with lateralisation ratios between three and four were discussed at a multi-disciplinary meeting to decide on subtype and treatment modality.

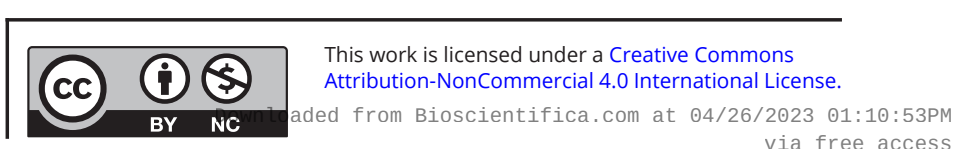


All patients treated with surgery underwent unilateral adrenalectomy via a minimally invasive transabdominal laparoscopic approach.

\section{Assessment of HRQoL and psychological symptoms}

HRQoL was assessed at baseline before treatment, 6 months, and 1 year post-treatment using two validated questionnaires: RAND 36-Item Health Survey (13) and the EQ-5D-3L (14) instrument. Depressive symptoms were assessed with the Beck Depression Inventory-II (BDI-II) (15). RAND-36 comprises 36 questions evaluating eight domains: physical functioning (PF), role limitations due to physical problems (RP), role limitations due to emotional problems (RE), vitality (VT), mental health (MH), social functioning (SF), bodily pain (BP), and general health perception (GH). The physical component summary (PCS) and mental component summary (MCS) are summations of the eight weighted subscale domains, and a national normative scoring is utilised where 50 indicates the adjusted mean and 10 is the standard deviation (S.D.) of the general population in Singapore $(16,17)$. A higher score represents a higher HRQoL. Question 2 addresses perceived health change (HC) compared to general health 1 year ago and is reported separately (range 0 to 100).

EQ-5D-3L comprises five questions relating to five dimensions of mobility, self-care, usual activity, pain/ discomfort, and anxiety/depression (14). Within each dimension, responses are divided into 'no problems', 'some or moderate problems' or 'extreme problems', and the scores are tabulated using weighted item score into a summary index (EQ-5D index score) according to the general populations norms in Singapore (18). The index score is represented by the utility or 1 - disutility. A factor loading score is subtracted from an original utility of 1 for any dimension faring worse than 'no problems'. An additional factor score is subtracted if the patient reports 'extreme problems' for any of the dimensions. This would result in a final score between the range of -0.7694 to 1 , where 1 is the best possible outcome (18). A visual analogue scale (EQ-VAS) allows patients to rate their current health status on a range from 0 to 100 , and a higher score represents better health status. Since most patients reported 'no problems', we performed binary grouping, with patients reporting 'no problems' separated from those patients with moderate or extreme problems.

BDI-II comprises 21 questions relating to various aspects of depressive symptoms, which can be broadly grouped into cognitive, affective, and somatic symptoms (15).
Within each domain, responses are divided into four choices, which will be converted into score of $0,1,2$, or 3 , and the scores are computed into a tallied score between the range of 0-63 (BDI score). A higher score represents more depressive symptoms. We have categorised the results into 0-13 (minimal depressive symptoms) vs 14-63 (mild to severe depressive symptoms) (15). We used the 3 -factors model proposed by Buckley et al. where each of the 21 questions is separated into three different factors using the factor loading score of how each question is specific to a certain domain $(19,20)$. A higher score denotes more severe symptoms in the particular domain (19). Additional analysis was done to compare patients who reported a score of 0 (no complaint) vs $>0$ (some degree of complaint) for each question.

\section{Statistical analysis}

Statistical analysis was performed using SPSS version 26.0 (IBM Corp.). Continuous variables were expressed as mean (s.D.) or median (IQR), and compared using independent $t$-test or Mann-Whitney $U$-test as appropriate. Chi-square test was used for categorical variables. Statistical significance was set at $P$ value less than 0.05 . For the analysis of the treatment outcome on RAND-36 subscales and summary scores, EQ-5D VAS, and BDI score after 6 months and 1 year, paired $t$-test was used to compare with baseline. For comparison with the general population, an independent $t$-test was used for RAND-36 subscales, RAND-36 summary score, and EQ-VAS (17). For comparison of EQ-5D index score and RAND-36 health changes compared to 1 year ago, Wilcoxon signed-rank test was used (18). Patients were included if they had filled up a baseline questionnaire.

\section{Results}

Eighty-six patients underwent a saline infusion test, 61 patients were confirmed with PA (Fig. 1), and 4 patients declined to participate. Fifty-seven patients were recruited into the main study with 23 excluded as they did not complete the baseline questionnaires. All patients included in the study who underwent saline infusion had post-saline $\mathrm{PAC} \geq 162 \mathrm{pmol} / \mathrm{L},(21,22)$ except for one patient (with $\mathrm{PAC} 140 \mathrm{pmol} / \mathrm{L}$ ). The remaining 34 were included in this study for assessing HRQoL and psychological symptoms, of which mean age is 51.3 years and $29.4 \%$ were females. Twenty-one patients were treated with surgery while 13 were treated with medications (Table 1). Thirty-three
This work is licensed under a Creative Commons Attribution-NonCommercial 4.0 International License. ded from Bioscientifica.com at 04/26/2023 01:10:53PM via free access 


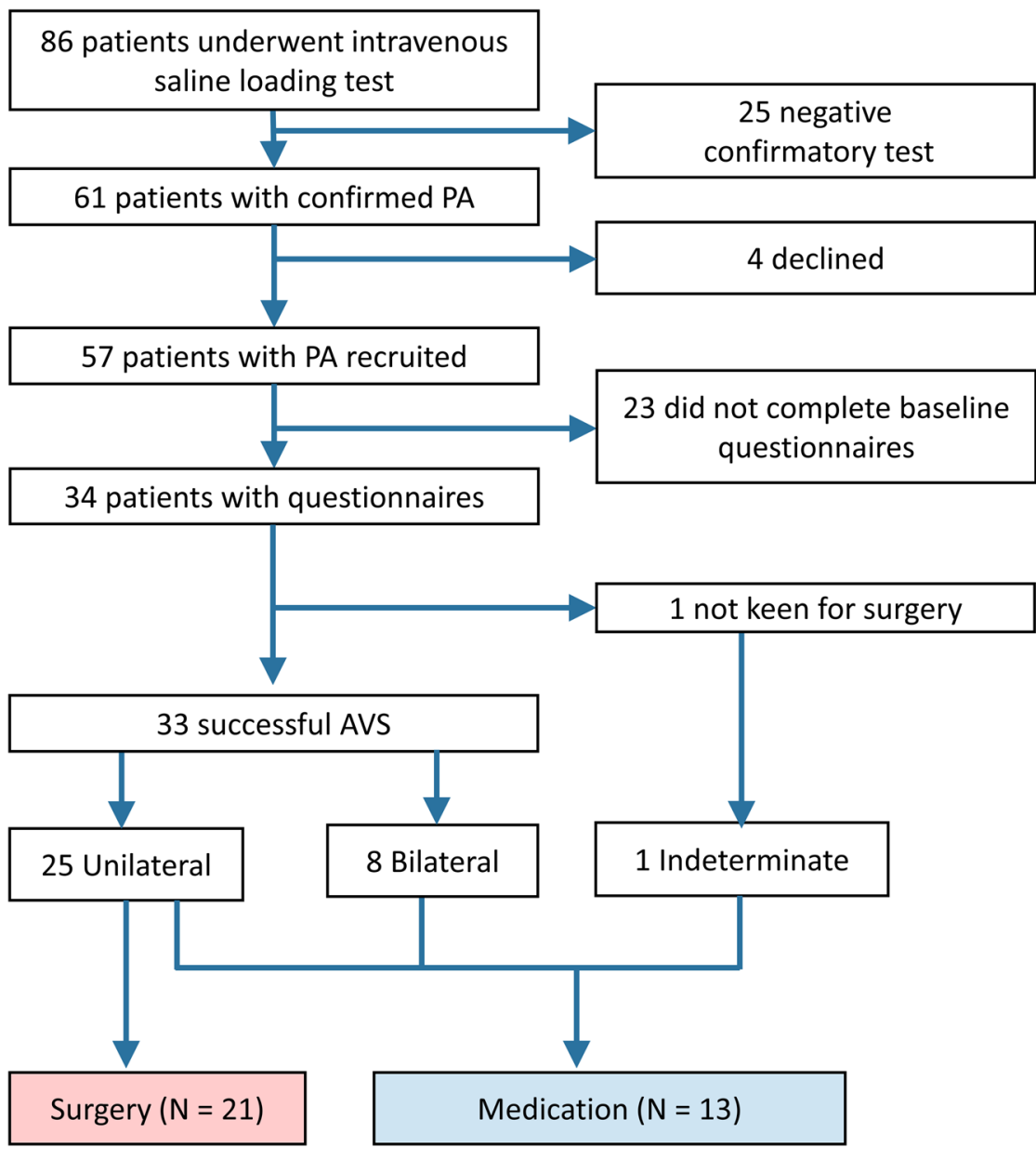

Figure 1

Consort diagram of patients included in the study with questionnaires. patients underwent AVS with all having successful bilateral cannulation. Twenty-five patients had lateralisation on AVS, with 21 undergoing unilateral adrenalectomy. The remaining four patients did not proceed with surgery: two patients had borderline lateralisation ratio (both 4.1), one patient changed her mind, one patient delayed surgery for personal reasons and is on interim medical therapy.

Twenty-nine patients filled out EQ-5D (English), and five patients filled out EQ-5D (Chinese) version. 76.5\% of the patients were Chinese, $11.8 \%$ Malays, 5.9\% Indians, and $5.9 \%$ others, which is similar to the population demographics. Patients treated with surgery were younger and had lowest-ever recorded serum potassium. There were otherwise no significant differences between the groups. Patients who completed questionnaires were younger, had higher eGFR and lower prevalence of hyperlipidemia, compared to those without questionnaires filled as shown in Supplementary Table 1 (see section on supplementary materials given at the end of this article). The remaining baseline characteristics between the groups were otherwise similar.

\section{Baseline}

At baseline, there were no significant differences between the two treatment groups in all eight RAND-36 domains, PCS, MCS, EQ-5D index or EQ-5D VAS (Table 1). At baseline, when compared to the reference population, there was no significant difference in baseline RAND-36 or EQ-5D observed in our study cohort.

\section{RAND-36}

At 6 months, while there was an improvement in all the variables, none of them reached statistical significance. At 1 year, there were significant improvements in four domains of physical functioning $(+7.02$ (95\% CI: 0.312-13.72)), bodily pain (+7.41 (95\% CI: 0.284-14.53)), role emotional (+11.11 (95\% CI: 0.767-21.46)), mental health $(+5.85$ (95\% CI: 2.00-9.71)), as well as both summative scores PCS (+3.65 (95\% CI: 0.555-6.75)) and MCS (+3.41 (95\% CI: 0.291-6.52)) (Fig. 2). In addition, there was an improvement in perceived health changes

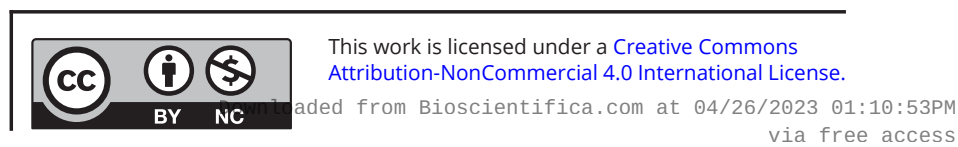


Table 1 Baseline characteristics of 34 patients with primary aldosteronism who has completed baseline questionnaire.

\begin{tabular}{l}
\hline \\
Age (years) \\
Gender, females (\%) \\
Ethnicity (\%) \\
Chinese \\
Malay \\
Indian \\
Others \\
BMI (kg/m ${ }^{2}$ ) \\
Systolic blood pressure \\
Diastolic blood pressure \\
BP Meds, DDD \\
Lowest K \\
eGFR \\
Years of hypertension ( $n=27$ ) \\
Ischeamic heart dsease (\%) \\
CKD (\%) \\
Cerebrovascular accident (\%) \\
Hyperlipidaemia (\%) \\
Diabetes mellitus (\%) \\
CT scan results (\%) \\
Unilateral adenoma \\
Bilateral abnormalities \\
Bilateral normal \\
EQ-5D index score \\
EQ-5D VAS $(n=31)$ \\
BDI score ( $n=28$ ) \\
RAND-36 ( $n=29$ ) \\
Subscales \\
Physical functioning \\
Role physical \\
Bodily pain \\
General health \\
Vitality \\
Social functioning \\
Role emotional \\
Mental health \\
PCS \\
MCS \\
Health changes \\
\end{tabular}

\begin{tabular}{c}
\hline Total $(n=34)$ \\
\hline $51.3(11.4)$ \\
$10(29.4 \%)$ \\
$26(76.5 \%)$ \\
$4(11.8 \%)$ \\
$2(5.9 \%)$ \\
$2(5.9 \%)$ \\
$27.5(5.4)$ \\
$149.1(16.9)$ \\
$86.0(8.9)$ \\
$3.1(2.2)$ \\
$2.7(0.5)$ \\
$88.6(18.8)$ \\
$9.0(0-24.0)$ \\
$3(8.8 \%)$ \\
$2(5.9 \%)$ \\
$3(8.8 \%)$ \\
$13(38.2 \%)$ \\
$12(35.3 \%)$ \\
$23(67.6 \%)$ \\
$2(5.9 \%)$ \\
$9(26.5 \%)$ \\
$1.00(0.850-1.00)$ \\
$80.6(12.9)$ \\
$6.2(8.3)$ \\
$82.9(18.5)$ \\
$77.6(36.2)$ \\
$83.5(21.6)$ \\
$67.1(17.9)$ \\
$71.2(18.6)$ \\
$82.3(25.6)$ \\
$83.9(32.9)$ \\
$79.1(17.8)$ \\
$50.8(8.2)$ \\
$52.7(11.3)$ \\
$50.0(25.0-75.0)$ \\
\end{tabular}

\begin{tabular}{c}
\hline Surgical $(n=21)$ \\
\hline $48.1(11.4)$ \\
$8(38.1 \%)$ \\
$16(76.2 \%)$ \\
$4(19.0 \%)$ \\
$0(0 \%)$ \\
$1(4.8 \%)$ \\
$26.9(5.3)$ \\
$148.1(16.7)$ \\
$86.0(10.1)$ \\
$3.2(1.9)$ \\
$2.4(0.4)$ \\
$88.45(20.3)$ \\
$8.0(0-23.0)$ \\
$1(4.8 \%)$ \\
$2(9.5 \%)$ \\
$3(14.3 \%)$ \\
$7(33.3 \%)$ \\
$7(33.3 \%)$ \\
$16(76.2 \%)$ \\
$1(4.8 \%)$ \\
$4(19.0 \%)$ \\
$1.00(0.850-1.00)$ \\
$82.1(11.4)$ \\
$6.0(8.9)$
\end{tabular}

\begin{tabular}{c}
\hline Medical $(n=13)$ \\
\hline $56.4(9.6)$ \\
$2(15.4 \%)$ \\
$10(76.9 \%)$ \\
$0(0 \%)$ \\
$2(15.4 \%)$ \\
$1(7.7 \%)$ \\
$28.6(5.6)$
\end{tabular}

\begin{tabular}{l}
\hline \multicolumn{1}{c}{$\boldsymbol{P}$} \\
\hline 0.036 \\
0.16 \\
0.12 \\
\end{tabular}

$150.7(17.8)$

0.37

$85.9(7.0)$

0.68

$3.0(2.7)$

$3.1(0.4)$

88.8 (16.9)

$20.0(3.0-37.0)$

$2(15.4 \%)$

$0(0 \%)$

$0(0 \%)$

$6(46.2 \%)$

5 (38.5\%)

0.98

0.78

$<0.001$

0.96

0.21

0.29

0.25

0.15

0.46

0.76

0.40

7 (53.8\%)

$1(7.7 \%)$

$5(38.5 \%)$

$1.00(0.850-1.00)$

0.89

78.5 (14.9)

0.46

$6.6(7.9)$

0.87

\begin{tabular}{l}
$83.3(18.7)$ \\
$79.2(32.4)$ \\
$86.3(18.7)$ \\
$68.1(18.5)$ \\
$72.2(16.8)$ \\
$86.1(19.1)$ \\
$81.5(34.7)$ \\
$79.8(17.9)$ \\
$51.0(7.9)$ \\
$53.8(10.6)$ \\
$50.0(19.0-81.0)$ \\
\hline
\end{tabular}

$82.3(19.2)$

0.88

$75.0(43.3)$

0.77

79.1 (25.9)

0.40

65.5 (17.7)

0.71

$69.6(22.0)$

0.71

76.1 (33.8)

0.32

$87.9(30.8)$

0.62

$78.0(18.5)$

0.80

$50.4(9.1)$

0.87

$51.1(12.6)$

0.54

$50.0(50.0-50.0)$

0.81

Values are presented in mean (S.D.), median (interquartile range) or number (percentage).

BP Meds, blood pressure medications; CKD, chronic kidney disease; DDD, defined daily dose; eGFR, estimated glomerular filtration rate; K, potassium; MCS, mental component summary; PCS, physical component summary; VAS, visual analogue score.

from baseline. Stratified by treatment groups, significant improvements in mental health, $P=0.033$, and PCS, $P=0.048$, were seen in the surgical group, but none of the variables reached statistical significance in the medical group (Table 2). At 1 year, mean values of all the domains were lower in the medical compared to the surgical group, although none were statistically significant. Stratified by gender, significant improvements were seen for females in the MCS subscale, as well as four domains (physical functioning, bodily pain, general health and mental health), whereas this was not seen in male patients as seen in Supplementary Table 2.

https://ec.bioscientifica.com

https://doi.org/10.1530/EC-21-0125

(c) 2021 The authors Published by Bioscientifica Ltd

\section{EQ-5D}

In the entire cohort, improvements in five dimensions and the EQ-5D index score were not statistically significant when compared to baseline post-treatment (Table 3). Similarly, the VAS score changed from $80.6(12.9)$ at baseline to 82.6 (9.0) at 1 year post-treatment, $P=0.14$. However, when stratified by treatment, there was a significant improvement in EQ-5D index score in the surgical group post-treatment, from 1.00 (IQR 0.85-1.00) to 1.00 (IQR 1.00-1.00), $P=0.034$, but this was not significant in the medical group. In addition, at 1 year post-treatment, there were more patients in the surgical

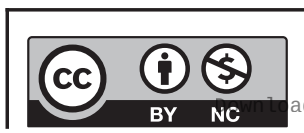

This work is licensed under a Creative Commons Attribution-NonCommercial 4.0 International License. ded from Bioscientifica.com at 04/26/2023 01:10:53PM via free access 


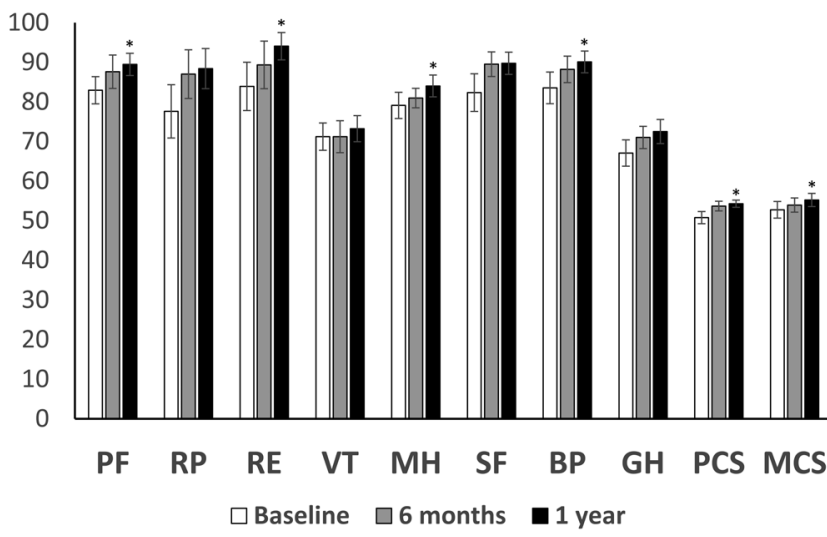

Figure 2

RAND-36 8 domains + PCS and MCS mean score in cohort of patients $(n=30)$.

group who had no issues overall compared to the medical group, $90 \%$ vs $58.3 \%, P=0.036$. In male patients, 12 of 12 $(100 \%)$ had no issues 1 year post-adrenalectomy, compared to 5 of $10(50 \%)$ post-medical therapy, $P=0.005$ seen in Supplementary Table 3 . Differences between treatment methods were not evident for females patients. At 1 year post-treatment, females had a better VAS score of 88.5 (7.1) compared to males 79.9 (8.6), $P=0.010$.

\section{BDI-II}

The overall BDI score was $6.2(8.3)$ at baseline, which improved to $4.4(6.2)$ at 6 months, $P=0.60$, and 4.2 (6.2) at 1 year post-treatment, $P=0.050$ (Table 4). At baseline, $10.3 \%$ had at least mild depression, with $8.0 \%$ at 6 months, $P=0.60$, and $7.1 \%$ at 1 year, $P=0.64$. At baseline, 37.9, 41.4, and $58.6 \%$ of patients endorsed symptoms in the cognitive, affective, and somatic domains of the BDI-II, respectively. At 1 year post-treatment, there was a significant improvement in the mean affective domain score of BDI, from 1.3 (2.0) to 0.64 (1.1), $P=0.010$, while there were no significant changes in cognitive and somatic domains. Stratified by treatment modality, there was no difference in BDI-II outcomes between the surgical and medically treated patients shown in Supplementary Table 4.

Amongst 21 patients treated with surgery, $14.3 \%$ had controlled BP at baseline which increased to $38.1 \%$ at 1 year post-surgery, while $85.7 \%$ had potassium $\geq 3.5 \mathrm{mmol} / \mathrm{L}$ at baseline, which increased to $95.2 \%$ at 12 months postsurgery. Amongst 13 patients treated with medications, 7.7\% had controlled BP at baseline, which increased to $30.8 \%$ at 12 months post-treatment, while $76.9 \%$ had potassium $\geq 3.5 \mathrm{mmol} / \mathrm{L}$ at baseline, which increased

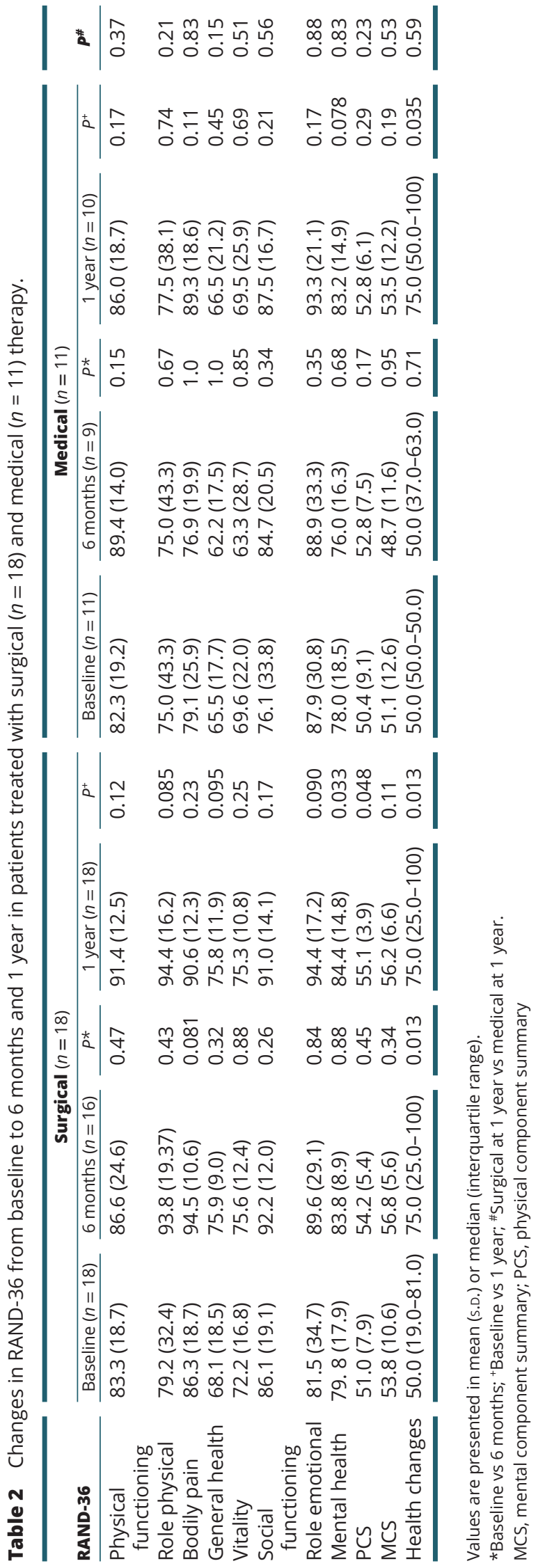




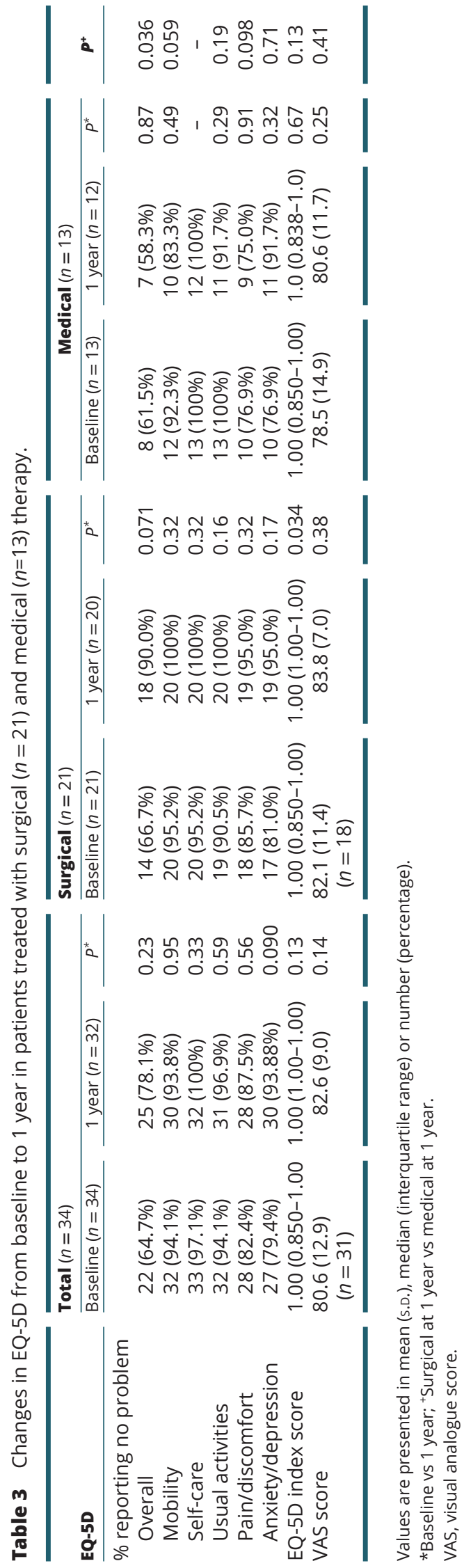

to $84.6 \%$ at 12 months post-treatment. There were no significant differences in the proportion of patients with controlled blood pressure or potassium $\geq 3.5 \mathrm{mmol} / \mathrm{L}$ between the surgically and medically treated groups. There were no differences in HRQoL between patients with controlled BP or potassium, compared to those without controlled BP or potassium.

\section{Discussion}

In this prospective observational study, we found that treatment for PA improved HRQoL in a multi-ethnic Asian cohort from baseline to 1 year after treatment. There were improvements in both summative scores, PCS and MCS, as well as four of eight RAND-36 domains. To our knowledge, this is the first prospective HRQoL study done in an Asian population and adds to those previously conducted in Caucasian patients $(5,10,11)$. In addition to the HRQoL assessment, we also found that $10 \%$ of our cohort with no history of psychiatric illness had at least mild depression using the BDI-II. Previous studies have demonstrated that patients with PA may have more symptoms of depression and anxiety (23). All of our patients had successful bilateral cannulation on AVS which allowed accurate subtyping of PA and appropriate surgery for unilateral disease. With this, we also found that surgery led to better outcomes in HRQoL compared with medications, adding to other data currently supporting the superiority of surgery in terms of cardiovascular and renal outcomes (2). Furthermore, male patients generally responded better with surgery compared to medical therapy, which is likely due to the anti-androgenic side effects of MR antagonists.

Patient-perceived health outcomes have an increasingly important role in healthcare. One of the most widely used questionnaires is the RAND-36, a generic HRQoL questionnaire which captures multiple aspects of health in eight domains. Summative scores for physical (PCS) and mental (MCS) can be obtained, but these are weighted differently for different populations. For example, role emotional is more closely related to MCS than PCS in Asians (24). Despite these differences, we found that treatment led to improvements in both summative scores in our Asian cohort, similar to previous studies in Australia $(10,11)$ and Europe (5). In addition to causing hypertension, aldosterone excess has direct deleterious effects on various organs, leading to an increased risk of cardiovascular and renal disease. It may have similar effects on the brain as MR receptors are abundant in the CNS (25). Treatment of PA improved HRQoL in our patients,

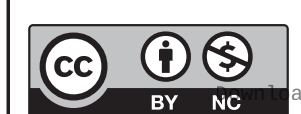

This work is licensed under a Creative Commons Attribution-NonCommercial 4.0 International License. ded from Bioscientifica.com at 04/26/2023 01:10:53PM via free access 
Table 4 Changes in BDI-II from baseline to 6 months and 1 year.

\begin{tabular}{l} 
BDI-II \\
\hline BDI score \\
\% with reported issue \\
CAT \\
Cognitive \\
Affective \\
Somatic \\
Cognitive \\
Affective \\
Somatic
\end{tabular}

\begin{tabular}{c}
\hline Baseline $(n=29)$ \\
\hline $6.2(8.3)(n=28)$ \\
$3(10.7 \%)(n=28)$ \\
$11(37.9 \%)$ \\
$12(41.4 \%)$ \\
$17(60.7 \%)(n=28)$ \\
$1.9(3.8)$ \\
$1.3(2.0)$ \\
$2.9(3.4)(n=28)$ \\
\hline
\end{tabular}

\begin{tabular}{c}
\hline 6 months $(n=25)$ \\
\hline $4.4(6.2)$ \\
$2(8.0 \%)$ \\
$7(28.0 \%)$ \\
$8(32.0 \%)$ \\
$18(72.0 \%)$ \\
$1.4(3.0)$ \\
$0.64(1.1)$ \\
$2.3(2.9)$ \\
\hline
\end{tabular}

\begin{tabular}{c}
\hline \multicolumn{1}{c}{$\boldsymbol{P}^{*}$} \\
\hline 0.60 \\
\\
0.74 \\
0.44 \\
0.48 \\
0.39 \\
0.81 \\
0.056 \\
0.83 \\
\hline
\end{tabular}

\begin{tabular}{c}
\hline 1 year $(n=28)$ \\
\hline $4.2(6.2)$ \\
$2(7.1 \%)$ \\
$5(17.9 \%)$ \\
$9(32.1 \%)$ \\
$20(71.4 \%)$ \\
$1.1(3.1)$ \\
$0.64(1.1)$ \\
$2.5(2.9)$ \\
\hline
\end{tabular}

\begin{tabular}{ll}
\hline \multicolumn{1}{c}{$\boldsymbol{P}^{+}$} \\
\hline 0.050 \\
\\
0.64 \\
0.092 \\
0.47 \\
0.40 \\
0.057 \\
0.010 \\
0.40 \\
\hline
\end{tabular}

Values are presented in mean (S.D.) or number (percentage).

*Baseline vs 6 months; ${ }^{+}$Baseline vs 1 year.

CAT, categorical grouping of 0-13 (minimal depressive symptoms) vs 14-63 (some form of depressive symptoms)

possibly due to resolution of the various manifestations of PA, such as improvement of hypertension, resolution of hypokalaemia (and muscle weakness) and nocturia. Interestingly, we did not find a poorer HRQoL at baseline in our cohort unlike previous studies (26). This could be due to differences in the perception of health and illness in Asian individuals from other ethnicities (27). We also found that some improvements were noted only after 1 year post-treatment. This suggests that improvements in HRQoL may extend beyond the initial 3-6 months similar to other beneficial effects such as blood pressure of which improvement might not be observed immediately upon treatment (28).

We found that surgical treatment for PA led to better outcomes in HRQoL compared with medical therapy, with improvements seen in PCS and the mental health domain of RAND-36, and EQ-5D index score, in the surgical group but not in the medical group. Velema and colleagues similarly found that patients treated with surgery had better HRQoL compared to those treated with medications (5). In addition, the higher defined daily dose (DDD) of antihypertensive medications was related to poorer HRQoL in patients treated with MR antagonists. Although MR antagonists are particularly effective for correcting both hypokalaemia and hypertension in PA, these medications may also worsen HRQoL due to its various side effects. In addition, there might be an incomplete blockade of mineralocorticoid receptors when treated with MR antagonists (5). While adrenalectomy leads to normalisation of aldosterone levels, patients on MR antagonists have persistent hyperaldosteronism which may continue to exert harmful effects via non-MR mediated mechanisms $(29,30)$. In addition, there has been evidence of excess glucocorticoid in patients with both unilateral and bilateral PA (31), which will not be adequately rectified with MR antagonists (32).
Differences in outcomes between men and women have been observed in previous studies. Women may report poorer HRQoL outcomes compared with men both at baseline and after treatment $(5,33)$. While there were no differences at baseline, we found that women had greater improvement in HRQoL compared to men and also better post-treatment EQ-5D visual score compared to men. This was likely explained by the poorer HRQoL seen in men on MR antagonists. We found that $50 \%$ of men had issues while on MR antagonists, compared with none having issues after surgery. Three of six patients initially started on spironolactone had anti-androgenic side effects, which required them to change to eplerenone. Another four were initiated on eplerenone and did not have any issues. The higher pill burden may also have contributed to poorer QOL seen in the medically treated group, with higher use of antihypertensive medication (DDD) at 1 year, $2.0(0-5.6)$, compared to the surgical group, $0.5(0-2.5), P=0.018$, which was also observed in the earlier study by Velema (5). In another study by Yoshida and colleagues which assessed only patients treated with MR antagonists, they found improvements in HRQoL after medical therapy, and less marked improvement in females compared to male patients. The difference between our studies may be due to the choice of MR antagonists used. Most of our patients were treated with spironolactone (69.2\%), compared with most patients in the study by Yoshida treated with eplerenone, which has less anti-androgenic side effects (26). Although MR antagonists may cause mastalgia or menstrual irregularities in women, due to its anti-androgenic effects, this is likely to be more distressing for men who may experience gynaecomastia and a decrease in libido. On the other hand, while MR antagonists may be better tolerated in women, surgical cure rates are higher in women who undergo adrenalectomy (34). Hence, there is a strong argument for pursuing subtype testing in both genders.

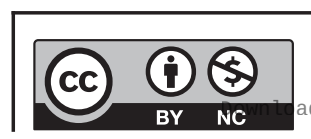

This work is licensed under a Creative Commons Attribution-NonCommercial 4.0 International License. ded from Bioscientifica.com at 04/26/2023 01:10:53PM via free access 
In addition to poorer HRQoL, patients with PA may have higher rates of depression and anxiety. Aldosterone has been shown to cause disturbances in psychological functions (35) and MR overactivity may play a role in depression, while MR antagonist may alleviate anxiety and depression (36). Depression is important to recognise as concomitant depression can lead to poor adherence to medications (37). While we have no population norms for comparison, our BDI-II mean score of 6.2 was generally low and comparable to cohorts of medical patients (38), with only $10.3 \%$ of patients classified with at least mild depressive symptoms. Somatic complaints were the most commonly endorsed symptom domain on the BDI-II with $58.6 \%$ reporting somatic complaints, including loss of energy, sleep disturbances, poorer appetite and fatigue. It is important to note that somatic complaints are not specific to depression and may be an effect of chronic illness (39). Nevertheless, with the high prevalence of stigma towards mental illness in Asians, who are less forthcoming in seeking psychiatric help, it is useful to screen and identify potential cases of depression for more detailed evaluation by mental health professionals (40). We observed a small but significant improvement in affective symptoms at 1 year post-treatment. This suggests that treatment of PA can improve patients' moods. Finally, there was no significant difference in anxiety and depression between our treatment groups, which is in line with a previous study (41).

This is the first study in an Asian cohort demonstrating improvement in HRQoL and depressive symptoms after treatment. Our prospective design reduces the risk of recall bias, and significant improvements were seen in our cohort at 1 year post-treatment. We recognise several limitations in our study. First, we included mainly English-literate patients for assessment of HRQoL who may respond differently to non-English-literate patients. The patients included were expectedly younger with higher eGFR but otherwise were similar in baseline characteristics. Furthermore, we had a high rate of recruitment (93\%), reducing the risk of healthy volunteer bias. Secondly, patients treated with surgery exclusively have unilateral PA, while most on medications have bilateral PA. Inherent differences between these groups may explain treatment differences. However, it is uncommon for patients with unilateral PA to be treated with medications, precluding this comparison. We previously compared treatment outcomes in only patients with unilateral PA and found better blood pressure outcomes with surgery (28). Thirdly, our cohort was relatively small and may have been underpowered to assess for differences between treatment groups. Nevertheless, we still found better outcomes with surgery than medical treatment, and our results are consistent with those in other cohorts. Finally, generic HRQoL questionnaires were used, and using disease-specific questionnaires may be better in identifying issues faced by patients with PA (e.g. nocturia), and also demonstrate greater improvements post-surgery. A recently developed PA-specific HRQoL questionnaire (42) may be usual in that regard and this will be an area worth studying in the future.

In conclusion, we found an improvement in HRQoL and depressive symptoms in patients with PA after surgical and medical treatment, with better outcomes observed after surgery. This underscores the importance of diagnosis of PA, accurate subtyping, and appropriate treatment to improve HRQoL and general well-being, in addition to other benefits of cardiovascular and renal outcomes.

\section{Supplementary materials}

This is linked to the online version of the paper at https://doi.org/10.1530/ EC-21-0125.

\section{Declaration of interest}

The authors declare that there is no conflict of interest that could be perceived as prejudicing the impartiality of the research reported.

\section{Funding}

This research did not receive any specific grant from any funding agency in the public, commercial or not-for-profit sector.

\section{Data availability statement}

The datasets generated and analysed during the current study are not publicly available but are available from the corresponding author on reasonable request.

\section{Acknowledgement}

The authors thank the staff of Clinical Trials and Research Unit, Changi General Hospital for their immense help in this study.

\section{References}

1 Bromfield S \& Muntner P. High blood pressure: the leading global burden of disease risk factor and the need for worldwide prevention programs. Current Hypertension Reports 201315 134-136. (https://doi. org/10.1007/s11906-013-0340-9)

2 Hundemer GL, Curhan GC, Yozamp N, Wang M \& Vaidya A. Cardiometabolic outcomes and mortality in medically treated primary aldosteronism: a retrospective cohort study. Lancet: Diabetes and Endocrinology 20186 51-59. (https://doi.org/10.1016/S22138587(17)30367-4)

3 Monticone S, D’Ascenzo F, Moretti C, Williams TA, Vegloi F, Gaita F \& Mulatero P. Cardiovascular events and target organ damage in primary aldosteronism compared with essential hypertension: a systematic review and meta-analysis. Lancet: Diabetes and 
Endocrinology 20186 41-50. (https://doi.org/10.1016/S22138587(17)30319-4)

4 Sonino N, Fallo F \& Fava GA. Psychological aspects of primary aldosteronism. Psychotherapy and Psychosomatics 200675 327-330. (https://doi.org/10.1159/000093956)

5 Velema M, Dekkers T, Hermus A, Timmers H, Lenders J, Groenewoud H, Schultze Kool L, Langenhuijsen J, Prejbisz A, van der Wilt GJ, et al. Quality of life in primary aldosteronism: a comparative effectiveness study of adrenalectomy and medical treatment. Journal of Clinical Endocrinology and Metabolism 2018103 16-24. (https://doi. org/10.1210/jc.2017-01442)

6 Funder JW, Carey RM, Mantero F, Murad MH, Reincke M, Shibata H, Stowasser M \& Young WF. The management of primary aldosteronism: case detection, diagnosis, and treatment: an endocrine society clinical practice guideline. Journal of Clinical Endocrinology and Metabolism 2016101 1889-1916. (https://doi.org/10.1210/jc.2015-4061)

7 Vonend O, Ockenfels N, Gao X, Allolio B, Lang K, Mai K, Quack I, Saleh A, Degenhart C, Seufert J, et al. Adrenal venous sampling: evaluation of the German Conn's Registry. Hypertension 201157 990-995. (https://doi.org/10.1161/HYPERTENSIONAHA.110.168484)

8 Skevington SM, Lotfy M, O'Connell KA \& WHOQOL Group. The World Health Organization's WHOQOL-bref quality of life assessment: psychometric properties and results of the international field trial a report from the WHOQOL Group. Quality of Life Research 200413 299-310. (https://doi.org/10.1023/B:QURE.0000018486.91360.00)

9 Testa MA \& Simonson DC. Assessment of quality-of-life outcomes. New England Journal of Medicine 1996334 835-840. (https://doi. org/10.1056/NEJM199603283341306)

10 Sukor N, Kogovsek C, Gordon RD, Robson D \& Stowasser M. Improved quality of life, blood pressure, and biochemical status following laparoscopic adrenalectomy for unilateral primary aldosteronism. Journal of Clinical Endocrinology and Metabolism 201095 1360-1364. (https://doi.org/10.1210/jc.2009-1763)

11 Ahmed AH, Gordon RD, Sukor N, Pimenta E \& Stowasser M. Quality of life in patients with bilateral primary aldosteronism before and during treatment with spironolactone and/or amiloride, including a comparison with our previously published results in those with unilateral disease treated surgically. Journal of Clinical Endocrinology and Metabolism 201196 2904-2911. (https://doi.org/10.1210/jc.20110138)

12 Puar TH, Loh WJ, Lim DST, Loh LM, Zhang M, Foo RS, Lee L, Swee DS, Khoo J, Tay D, et al. Aldosterone-potassium ratio predicts primary aldosteronism subtype. Journal of Hypertension 202038 1375-1383. (https://doi.org/10.1097/HJH.0000000000002348)

13 Ware JE \& Sherbourne CD. The MOS 36-item short-form health survey (Sf-36): I. Conceptual framework and item selection. Medical Care 1992 30 473-483. (https://doi.org/10.1097/00005650-199206000-00002)

14 EuroQol Group. EuroQol - a new facility for the measurement of health-related quality of life. Health Policy 199016 199-208. (https:// doi.org/10.1016/0168-8510(90)90421-9)

15 Beck AT, Steer RA \& Brown G. Beck Depression Inventory-II. London, UK: Pearson, 1996.

16 Ware JE, Kosinski MA \& Keller SD. SF-36 Physical and Mental Health Summary Scales. Boston, MA: Health Inst N. Engl. Med. Cent., 1994.

17 Thumboo J, Fong KY, Machin D, Chan SP, Soh CH, Leong KH, Feng PH, Thio St \& Boey ML. Quality of life in an urban Asian population: the impact of ethnicity and socio-economic status. Social Science and Medicine 200356 1761-1772. (https://doi.org/10.1016/s02779536(02)00171-5)

18 Luo N, Wang P, Thumboo J, Lim YW \& Vrijhoef HJM. Valuation of EQ-5D-3L health states in Singapore: modeling of time trade-off values for 80 empirically observed health states. Pharmacoeconomics 201432 495-507. (https://doi.org/10.1007/s40273-014-0142-1)

19 Buckley TC, Parker JD \& Heggie J. A psychometric evaluation of the BDI-II in treatment-seeking substance abusers. Journal of Substance
Abuse Treatment 200120 197-204. (https://doi.org/10.1016/s07405472(00)00169-0)

20 Vanheule S, Desmet M, Groenvynck H, Rosseel Y \& Fontaine J.

The factor structure of the beck depression inventory-II: an evaluation. Assessment 200815 177-187. (https://doi. org/10.1177/1073191107311261)

21 Stowasser M, Ahmed AH, Cowley D, Wolley M, Guo Z, McWhinney BC, Ungerer JP \& Gordon RD. Comparison of seated with recumbent saline suppression testing for the diagnosis of primary aldosteronism. Journal of Clinical Endocrinology and Metabolism 2018103 4113-4124. (https://doi.org/10.1210/jc.201801394)

22 Thuzar M, Young K, Ahmed AH, Ward G, Wolley M, Guo Z, Gordon RD, McWhinney BC, Ungerer JP \& Stowasser M. Diagnosis of primary aldosteronism by seated saline suppression test - variability between immunoassay and HPLC-MS/MS. Journal of Clinical Endocrinology and Metabolism 2020105 e477-e483. (https://doi. org/10.1210/clinem/dgz150)

23 Sonino N, Tomba E, Genesia ML, Bertello C, Mulatero P, Veglio F, Fava GA \& Fallo F. Psychological assessment of primary aldosteronism: a controlled study. Journal of Clinical Endocrinology and Metabolism 201196 E878-E883. (https://doi.org/10.1210/jc.2010-2723)

24 Tseng HM, Lu JR \& Gandek B. Cultural issues in using the SF-36 health survey in Asia: results from Taiwan. Health and Quality of Life Outcomes 20031 72. (https://doi.org/10.1186/1477-7525-1-72)

25 Geerling JC \& Loewy AD. Aldosterone in the brain. American Journal of Physiology: Renal Physiology 2009297 F559-F576. (https://doi. org/10.1152/ajprenal.90399.2008)

26 Yoshida Y, Yoshida R, Shibuta K, Ozeki Y, Okamoto M, Gotoh K, Masaki T \& Shibata H. Quality of life of primary aldosteronism patients by mineralocorticoid receptor antagonists. Journal of the Endocrine Society 20215 bvab020. (https://doi.org/10.1210/jendso/bvab020)

27 Chen X \& Swartzman LC. Health beliefs and experiences in Asian cultures. In Handbook of Cultural Health Psychology, pp. 389-410. Elsevier, 2001. (https://doi.org/10.1016/B978-012402771-8/50016-7)

28 Puar TH, Loh LM, Loh WJ, Lim DST, Zhang M, Tan PT, Lee L, Swee DS, Khoo J, Tay D, et al. Outcomes in unilateral primary aldosteronism after surgical or medical therapy. Clinical Endocrinology 202194 158-167. (https://doi.org/10.1111/cen.14351)

29 Saiki A, Otsuki M, Mukai K, Hayashi R, Shimomura I, Kurihara I, Ichijo T, Takeda Y, Katabami T, Tsuiki M, et al. Basal plasma aldosterone concentration predicts therapeutic outcomes in primary aldosteronism. Journal of the Endocrine Society 20204 bvaa011. (https:// doi.org/10.1210/jendso/bvaa011)

30 Dooley R, Harvey BJ \& Thomas W. Non-genomic actions of aldosterone: from receptors and signals to membrane targets. Molecular and Cellular Endocrinology 2012350 223-234. (https://doi. org/10.1016/j.mce.2011.07.019)

31 Arlt W, Lang K, Sitch AJ, Dietz AS, Rhayem Y, Bancos I, Feuchtinger A, Chortis V, Gilligan LC, Ludwig P, et al. Steroid metabolome analysis reveals prevalent glucocorticoid excess in primary aldosteronism. JCI Insight 20172 e93136. (https://doi.org/10.1172/jci.insight.93136)

32 Gerards J, Heinrich DA, Adolf C, Meisinger C, Rathmann W, Sturm L, Nirschl N, Bidlingmaier M, Beuschlein F, Thorand B, et al. Impaired glucose metabolism in primary aldosteronism is associated with cortisol cosecretion. Journal of Clinical Endocrinology and Metabolism 2019104 3192-3202. (https://doi.org/10.1210/jc.2019-00299)

33 Künzel HE, Apostolopoulou K, Pallauf A, Gerum S, Merkle K, Schulz S, Fischer E, Brand V, Bidlinmaier M, Endres S, et al. Quality of life in patients with primary aldosteronism: gender differences in untreated and long-term treated patients and associations with treatment and aldosterone. Journal of Psychiatric Research 201246 1650-1654. (https:// doi.org/10.1016/j.jpsychires.2012.08.025)

34 Williams TA, Lenders JWM, Mulatero P, Burrello J, Rottenkolber M, Adolf C, Satoh F, Amar L, Quinkler M, Deinum J, et al. Outcomes after https://ec.bioscientifica.com https://doi.org/10.1530/EC-21-0125 (c) 2021 The authors Published by Bioscientifica Lto

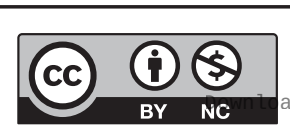

This work is licensed under a Creative Commons Attribution-NonCommercial 4.0 International License. ded from Bioscientifica.com at 04/26/2023 01:10:53PM 
adrenalectomy for unilateral primary aldosteronism: an International Consensus on Outcome Measures and Analysis of Remission Rates in an International Cohort. Lancet: Diabetes and Endocrinology 20175 689-699. (https://doi.org/10.1016/S2213-8587(17)30135-3)

35 MacKenzie SM, Lai M, Clark CJ, Fraser R, Gómez-Sánchez CE, Seckl JR, Connell JMC \& Davies E. 11 $\beta$-Hydroxylase and aldosterone synthase expression in fetal rat hippocampal neurons. Journal of Molecular Endocrinology 200229 319-325. (https://doi.org/10.1677/ jme.0.0290319)

36 Murck H, Büttner M, Kircher T \& Konrad C. Genetic, molecular and clinical determinants for the involvement of aldosterone and its receptors in major depression. Nephron: Physiology 2014128 17-25. (https://doi.org/10.1159/000368265)

37 Ciechanowski PS, Katon WJ \& Russo JE. Depression and diabetes: impact of depressive symptoms on adherence, function, and costs. Archives of Internal Medicine $20001603278-3285$. (https://doi. org/10.1001/archinte.160.21.3278)

38 Arnau RC, Meagher MW, Norris MP \& Bramson R. Psychometric evaluation of the beck depression inventory-II with primary care medical patients. Health Psychology 200120 112-119. (https://doi. org/10.1037//0278-6133.20.2.112)

39 Wang YP \& Gorenstein C. Assessment of depression in medical patients: a systematic review of the utility of the beck depression inventory-II. Clinics 201368 1274-1287. (https://doi.org/10.6061/ clinics/2013(09)15)

40 Lauber C \& Rössler W. Stigma towards people with mental illness in developing countries in Asia. International Review of Psychiatry 200719 157-178. (https://doi.org/10.1080/09540260701278903)

41 Apostolopoulou K, Künzel HE, Gerum S, Merkle K, Schulz S, Fischer E, Pallauf A, Brand V, Bidlingmaier M, Endres S, et al. Gender differences in anxiety and depressive symptoms in patients with primary hyperaldosteronism: a cross-sectional study. World Journal of Biological Psychiatry 201415 26-35. (https://doi.org/10.3109/15622975.2012.665 480)

42 Velema MS, Nooijer A, Hermus ARMM, Timmers HJLM, Lenders JWM, Husson $\mathrm{O} \&$ Deinum J. A disease-specific quality of life questionnaire for primary aldosteronism. Endocrine Connections 20198 389-397. (https://doi.org/10.1530/EC-19-0026)

Received in final form 18 June 2021

Accepted 5 July 2021

Accepted Manuscript published online 5 July 2021
This work is licensed under a Creative Commons Attribution-NonCommercial 4.0 International License. ded from Bioscientifica.com at 04/26/2023 01:10:53PM via free access 